\title{
Nucleation of sulfur hexafluoride
}

\author{
Peng Ye \\ Anne Bertelsmann \\ Richard H. Heist \\ Fairfield University, rheist@fairfield.edu
}

Follow this and additional works at: https://digitalcommons.fairfield.edu/engineering-facultypubs Copyright 2000 American Institute of Physics

The final publisher PDF has been archived here with permission from the copyright holder. https://doi.org/10.1063/1.1361803

\section{Repository Citation}

Ye, Peng; Bertelsmann, Anne; and Heist, Richard H., "Nucleation of sulfur hexafluoride" (2000).

Engineering Faculty Publications. 149.

https://digitalcommons.fairfield.edu/engineering-facultypubs/149

\section{Published Citation}

Ye, P., Bertelsmann, A., \& Heist, R. H. (2000, August). Nucleation of sulfur hexafluoride. In Nucleation and Atmospheric Aerosols 2000, AIP Conference Proceedings Vol. 534(1), pp. 19-22. AIP. Doi:10.1063/1.1361803.

This item has been accepted for inclusion in DigitalCommons@Fairfield by an authorized administrator of DigitalCommons@Fairfield. It is brought to you by DigitalCommons@Fairfield with permission from the rightsholder(s) and is protected by copyright and/or related rights. You are free to use this item in any way that is permitted by the copyright and related rights legislation that applies to your use. For other uses, you need to obtain permission from the rights-holder(s) directly, unless additional rights are indicated by a Creative Commons license in the record and/or on the work itself. For more information, please contact digitalcommons@fairfield.edu. 


\title{
Nucleation of Sulfur Hexafluoride
}

\author{
Peng Ye, Anne Bertelsmann ${ }^{\dagger}$ and Richard H. Heist*
}

Nucleation Laboratory, Department of Chemical Engineering

University of Rochester, Rochester, NY 14627-0166

\begin{abstract}
We measured the homogeneous nucleation of sulfur hexafluoride using a diffusion cloud chamber under conditions that avoid the possibility of non-diffusive modes of transport within the cloud chamber thus ensuring reliable data from our measurements. We extended the critical supersaturation measurements into the critical region for $\mathrm{SF}_{6}$ using helium as background gas.
\end{abstract}

\section{INTRODUCTION}

Based upon results of our nucleation experiments, it has become increasingly clear that homogeneous nucleation data obtained using current methods of experiment data analysis for thermal diffusion cloud chambers (TDCC) depend both on the amount and kind of background gas. ${ }^{1,2}$ With the development of the high pressure diffusion cloud chamber (HPCC) at Rochester, it is now feasible to expand useful nucleation measurements to wide ranges of both total pressure and nucleation temperature. ${ }^{1,3}$ In addition, it is through the increased functionality of the HPCC that we have been able to demonstrate, for the first time, the subtle and generally overlooked effects of buoyancy-driven convective flow and the importance of determining the proper ranges of the total pressure and TDCC plate temperatures before carrying out nucleation measurements. ${ }^{4,5}$

High Pressure Limit - The essential point in this regard pertains to maintaining the operational stability of the TDCC with respect to buoyancy-driven convective flow disturbances originating at the chamber wall. ${ }^{4}$ Fortunately, these flows can be predicted by determining, a priori, the upper limit of allowable total pressure in the TDCC. ${ }^{4}$ Results of a recent analysis have confirmed our hypothesis regarding the formation, existence, and deleterious effects of buoyancy-driven convective instabilities in the TDCC arising from density inversions at the chamber wall. ${ }^{6}$

Low Pressure Limit - Based on recent investigations from our laboratory, we know that there is also a lower limit of allowable total pressure within the diffusion cloud chamber. ${ }^{5}$ This lower limit does not relate in a meaningful way to the commonly used "pressure ratio" and must be determined empirically. At too low total pressures, we have found that the cloud chamber no longer functions in a manner consistent with our current perception of the nature of the mass and energy transport processes occurring within the chamber. ${ }^{5}$

In this paper we report results of our investigation of the nucleation of sulfur hexafluoride obtained, for the first time, using HPCC. We used the analytic and 
empirical procedures referred to above to determine the proper range of operation of the HPCC before we made the quantitative measurements we present below. We report results of constant total pressure and constant nucleation temperature measurements with helium as the background gas. We also report preliminary measurements of $\mathrm{SF}_{6}$ nucleation at temperatures approaching the critical point.

\section{EXPERIMENT RESULTS}

The HPCC employed in this investigation has been described in detail elsewhere. ${ }^{1,3}$ The behavior of the vapor-gas mixture is described using the PengRobinson equation of state and an interaction parameter $k_{12}$. In our thermodynamic analysis we account for the non-ideal behavior of the gas phase, pressure effects (Poynting correction), and background gas solubility in the liquid.

Constant total pressure critical supersaturation $\left(\mathrm{S}_{\mathrm{cr}}\right)$ experiments using $\mathrm{SF}_{6}$ with helium as a background gas were conducted at $30,40,50,60$ bar. The results are presented in Figure 1. The important point to note is that each of these series of curves, with their corresponding envelope (not shown), shifts to larger values of the $\mathrm{S}_{\mathrm{cr}}$ as the total pressure increases. The shift is more pronounced at lower temperatures.

Critical supersaturation experiments using $\mathrm{SF}_{6}$ and helium were conducted at constant nucleation temperatures of $253.5,261.9,268.1,275.8,285.0$ and $305.7 \mathrm{~K}$. Figure 2 shows the results of these experiments. In the analysis of this data, the value of $S_{\mathrm{cr}}$ was obtained using classical nucleation theory (BDZ) to identify the height of the nucleation plane. The solid lines shown on these graphs have been regressed to the data for each temperature.

We also conducted constant pressure $S_{c r}$ studies using $S_{6}$ in which the nucleation temperature ranged between 8 to $18 \mathrm{~K}$ of the critical temperature $(318.7 \mathrm{~K})$. These experiments were performed at total pressures of 60,65 and 70 bar using helium as a background gas. The results are shown in Figure 3. For the purpose of clarity, the result of each experiment is represented as a single point (as in the constant temperature experiments) rather than a curve segment. For comparison, we have included the $\mathrm{S}_{\mathrm{cr}}$ predicted by BDZ theory.

\section{DISCUSSION OF EXPERIMENT RESULTS}

Pressure Dependence - We find from our experiments involving $\mathrm{SF}_{6}$ in helium that the $S_{\mathrm{cr}}$ as determined for the HPCC depends on total pressure. As can be seen in Figure 1, the supersaturation versus temperature curve segments shift toward higher supersaturation as the total pressure is increased. This shift is more pronounced at lower temperatures and appears to vanish the critical point is approached. This behavior can also be seen in results from our constant temperature experiments shown in Figure 2. The $S_{\mathrm{cr}}$ increases linearly with total pressure, and the slope of the regressed curves represents the magnitude of the total pressure effect. This observed dependence is entirely consistent with the total pressure dependence observed in our earlier experiments involving the lower molecular weight alcohols. 
In Figure 4, we compare selected results of the constant total pressure experiments (at 50 bar) to the results of the constant nucleation temperature experiments. The curve segments are the results from constant pressure experiments (Figure 1). The solid circles represent the values of supersaturation and temperature corresponding to the maximum calculated nucleation rate for each curve segment. The open triangles were obtained from the regressed $S_{\mathrm{cr}}$ versus total pressure curves (Figure 2). Agreement between the two different types of experiments is good. ${ }^{2}$

Experiments Near the Critical Point - The data shown in Figure 3 represent the variation of the $\mathrm{S}_{\mathrm{cr}}$ of $\mathrm{SF}_{6}$ with temperature at a variety of total pressures ranging from 60 to $70 \mathrm{bar}$. Each point corresponds to the maximum nucleation rate for each experiment determined using BDZ theory. The open region between the data shown in Figure 3 from roughly $297 \mathrm{~K}$ to $301 \mathrm{~K}$ resulted from our changing heat exchangers during our experiments and the non-overlap of their accessible ranges. The prediction of BDZ theory is included as a reference. In Figure 3, we note the coincidence of the nucleation data obtained at each of the different total pressures. This is the first experimental verification of our earlier prediction that the dependence of nucleation on total pressure would vanish as the critical point is approached. ${ }^{1,2,7}$ We note in Figure 3 that at temperatures below approximately $301 \mathrm{~K}$ the variation of the $S_{\mathrm{cr}}$ with temperature seems to decrease in the anticipated concave fashion. At approximately $301 \mathrm{~K}$ the variation of the data appears to abruptly change slope, become somewhat flat and then decrease in a convex fashion as the temperature increases. This is the same dependence of the $S_{\mathrm{cr}}$ with temperature we observed with n-hexane and helium near the critical point of $n$-hexane. ${ }^{3}$ While this data is preliminary and presented here to demonstrate the apparent existence of this interesting trend, it is consistent with the predictions of the McGraw and Reiss theory. ${ }^{8}$ Vapor to liquid nucleation measurements in the critical region are rather rare, and these data strongly suggest the need to continue these investigations.

\section{SUMMARY AND CONCLUSIONS}

We measured the homogeneous nucleation of $\mathrm{SF}_{6}$ using the HPCC. We determined the range of proper operation of the $\mathrm{HPCC}$ for $\mathrm{SF}_{6}$ - helium in order to avoid the possibility of convective transport within the cloud chamber. We observed that $\mathrm{SF}_{6}$ nucleation depends on the total pressure. These observations are entirely consistent with results of earlier investigations from our laboratory. ${ }^{1,2,7}$ Nucleation measurements made at constant total pressure and constant temperature are in good agreement. We extended the $S_{\mathrm{cr}}$ measurements into the critical region since such measurements are rare. We observed a change in the dependence of the $S_{\mathrm{cr}}$ with temperature (at constant pressure) in the critical region that appeared to be consistent with predictions of the theory of McGraw and Reiss. ${ }^{8}$

\footnotetext{
* Current address: School of Engineering, Manhattan College, Riverdale, NY 10471

$\uparrow$ Current address: Bayer Corporation, Baytown, TX
} 

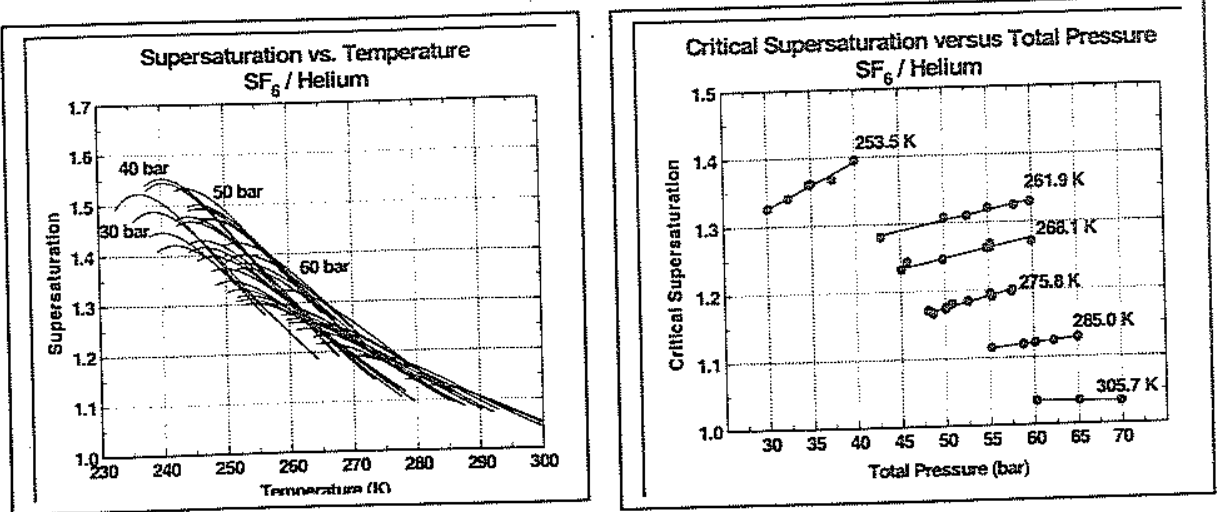

FIGURE 1. Variation of the critical supersaturation of $\mathrm{SF}_{6}$ with temperature at $30,40,50$ and 60 bar.

FIGURE 2. Variation of the critical supersaturation of $\mathrm{SF}_{6}$ with total pressure.
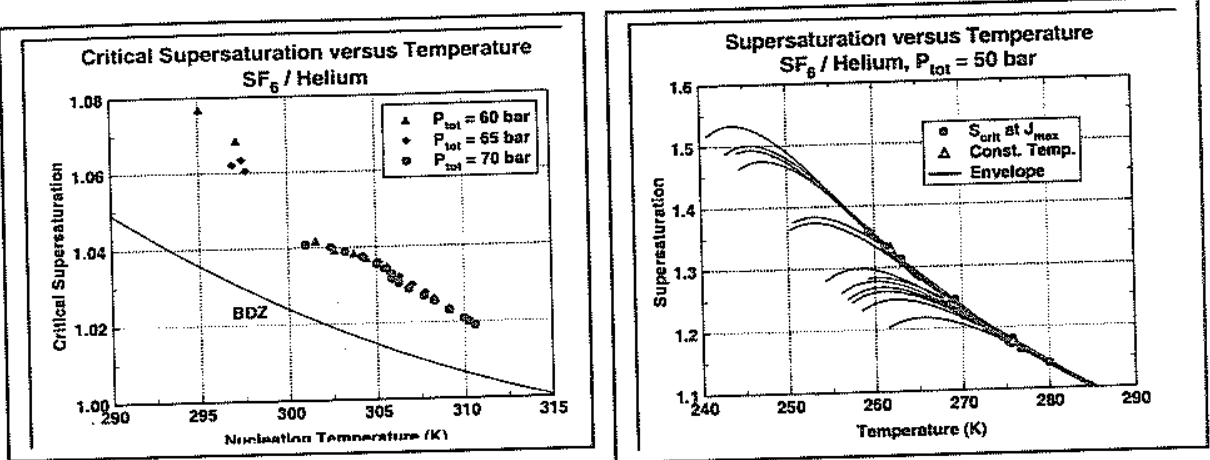

FIGURE 3. Variation of the critical supersaturation of $\mathrm{SF}_{6}$ at with temperature at 60,65 and 70 bar near the critical point. Prediction of the BDZ theory is included for comparison.

FIGURE 4. Comparison of constant pressure and constant temperature experiments, for $\mathrm{SF}_{6}$ at 50 bar. The thick line represents the envelope, the curve segments the computed supersaturation profiles, and the solid dots mark the location of maximum rate on each curve. The open triangles represent the critical supersaturation obtained from constant temperature experiments.

\section{RQRERENCES}

1. Heist, R. H.; Janjua, M.; Ahmed, J. J. Phys. Chem.,98, 4443 (1994).

2. Bertelsmann, A., Stuczynski, R. and Heist, R.H., J. Phys Chem., 100, 9762 (1996).

3. Heeks, M., M.S. Thesis, University of Rochester, (1983).

4. Bertelsmann, A. and Heist, R.H., J. Chem. Phys, 106, 324 (1997).

5. Heist, R.H., Bertelsmant, A., Martinez, D. and Chan, Y.K., J. Phys. Chem. (2000), submitted,

6 Ferguson, F.T. and Nuth, J.A., II, J. Chem. Phys., 111, 8013 (1999).

7. Bertelsmann, A. and Heist, R.H., J. Aerosol Science and Technology, 28, 259 (1998).

8. (a) McGraw, R. and Reiss, H., J. Stat. Phys., 20, 385 (1979); (b) McGraw, R., J. Chem. Phys., 91 , 5655 (1989). 